\title{
Infusion Rate
}

National Cancer Institute

\section{Source}

National Cancer Institute. Infusion Rate. NCI Thesaurus. Code C94916.

The volume of a substance injected into a subject in a unit time. 